\title{
APPLICATION OF RADIOIMMUNOASSAY FOR TESTOSTERONE TO ROUTINE TESTING
}

\author{
C. BOUDENE, Ph.D.(Pharm. \& Tox.), J. M. JOUANY, Ph.D.(Pharm. \& Tox.), \\ J. BELEGAUD, Ph.D.(Pharm. \& Tox.) and Nicole DESPAUX, Ph.D.(Pharm. \& Tox.)
}

Faculté des Sciences Pharmaceutiques et Biologiques de l'Université Paris-Sud, Rue J. B. Clément, 92290 Chatenay-Malabry, France

\section{Introduction}

Radioimmunoassays (RIA) theoretically take into account the two main criteria for toxicological studies, sensitivity because of the use of labelled compounds and specificity related to the immunologic systems involved.

The method of determination proposed for insulin by Yalow and Berson (1960) was used later for hormones and drugs or toxic substances difficult to determine by other techniques.

RIA allows analysis of large series of samples and may be used in routine testing.

We have tried to adapt this kind of technique to the detection of testosterone in horse urine and saliva. This first paper deals only with free testosterone to try to avoid hydrolysis of the samples which is time consuming and might not be necessary for routine controls.

Testosterone was measured using the radioimmunoassay kit supplied by CEA-IRE-SORIN. Testosterone labelled with tritium was incubated with the residue from evaporation of an ether extract of urine. Free and bound fractions were separated with charcoal, and tritium levels measured by liquid scintillation counting.

\section{Results}

As we are working in routine in blind conditions, only knowing the registered number of the samples, we have selected abitrarily 155 urines and salivas of winners and measured the free testosterone in them.

Afterwards, we were told the sex and the age of the horses which had been tested. Table I shows the distribution, using urine samples.

The age of the groups increases from mares, through stallions to geldings (Fig. 1).

\section{Dose of Testosterone}

The determination did not work for saliva, too high levels being obtained, about 600 to 2000 or $3000 \mathrm{pg} / \mathrm{ml}$.

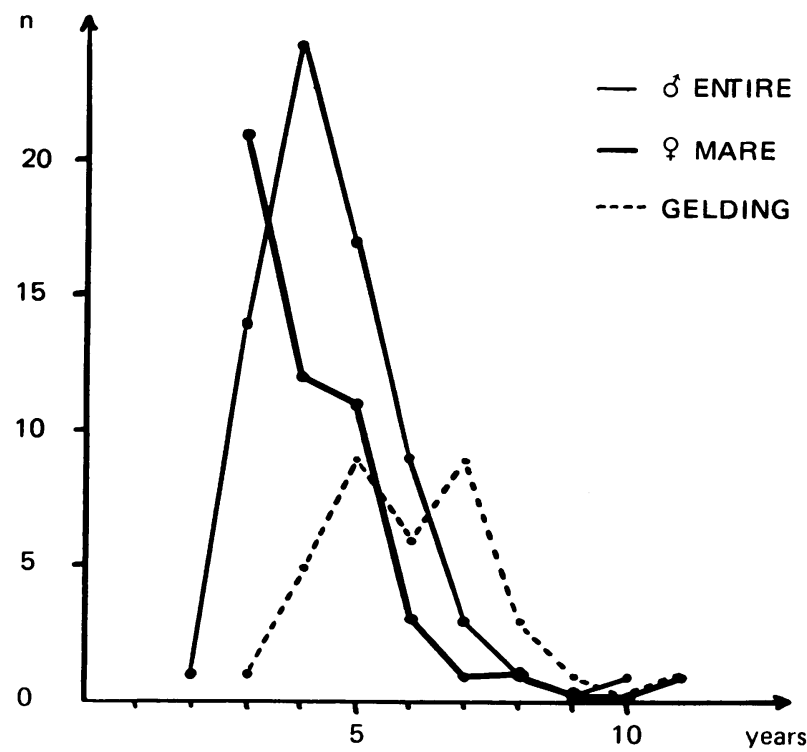

Fig. 1. Age of the winners, stallions, mares and geldings, in the urine of which free testosterone was determined.

\section{TABLE I}

Sex and Age of the Winners Tested for Free Testosterone in Urine

\begin{tabular}{|c|c|c|c|c|}
\hline $\begin{array}{l}\text { Age in } \\
\text { Years }\end{array}$ & Stallions & Mares & Geldings & total \\
\hline 2 & 1 & & & 1 \\
\hline 3 & 14 & 21 & 1 & 36 \\
\hline 4 & 24 & 12 & 5 & 41 \\
\hline 5 & 17 & 11 & 9 & 37 \\
\hline 6 & 9 & 3 & 6 & 18 \\
\hline 7 & 3 & 1 & 9 & 13 \\
\hline 8 & 1 & 1 & 3 & 5 \\
\hline 9 & 0 & 0 & 1 & 1 \\
\hline 10 & 1 & 0 & 0 & $i$ \\
\hline 11 & 0 & 1 & 1 & 2 \\
\hline total & 70 & 50 & 35 & 155 \\
\hline
\end{tabular}


To try to understand the interference, we applied the method of assay to pure solutions of mucopolysaccharrides $1 \%$ and $10 \%$. In each case, high values were obtained showing the definite interference of that kind of biological polymer. We therefore disregarded the results obtained with saliva.

\section{Means Values According to Age and Sex}

Table II summarizes the mean values found for the different horses according to the age. The standard deviation was calculated only when a sufficient number of results were obtained.

\section{TABLE II}

Mean Values of Free Testosteronc in Urine of Winners According to Age and Sex (in $\mathrm{pg} / \mathrm{ml}$ of urine)

$\begin{array}{rlll}\text { AGE } & \text { Stallions } & \text { Mares } & \text { Geldings } \\ 3 & 539 \pm 220 & 287 \pm 102 & 180 \\ 4 & 471 \pm 290 & 243 \pm 98 & 267 \pm 236 \\ 5 & 436 \pm 204 & 269 \pm 147 & 268 \pm 77 \\ 6 & 406 \pm 261 & 229 \pm 105 & 191 \pm 92 \\ 7 & 165 & 360 & 248 \pm 148 \\ 8 & 150 & 160 & 143 \\ 9 & & & 193 \\ 10 & 120 & & \\ 11 & & 360 & 353\end{array}$

The range of values, as shown by the standard deviations, are large, but overall, stallions have higher concentrations of testosterone than geldings, the latter resembling the results of the mares, as might be expected.

Looking at the histograms (Fig. 2), one may see, when all the values are put together (stallions + mares + geldings), that a bimodal partition could exist, with two maxima in the ranges of $100-200$ and $800-900 \mathrm{pg} / \mathrm{ml}$. When the histograms are done for each class of horse, it appears that the partition in two groups is very clear for stallions, which are eliminating more hormone than the others.

Figure 3 shows also, comparing stallions and females at the same age, that the amount of testosterone is greater in the male urine but decreases with age.

Some interesting concentrations can be encountered, above $1000 \mathrm{pg} / \mathrm{ml}$, but only in stallions.

\section{Conclusions}

It is suggested that the determination of testosterone by radioimmunoassay works well in urine, but not in
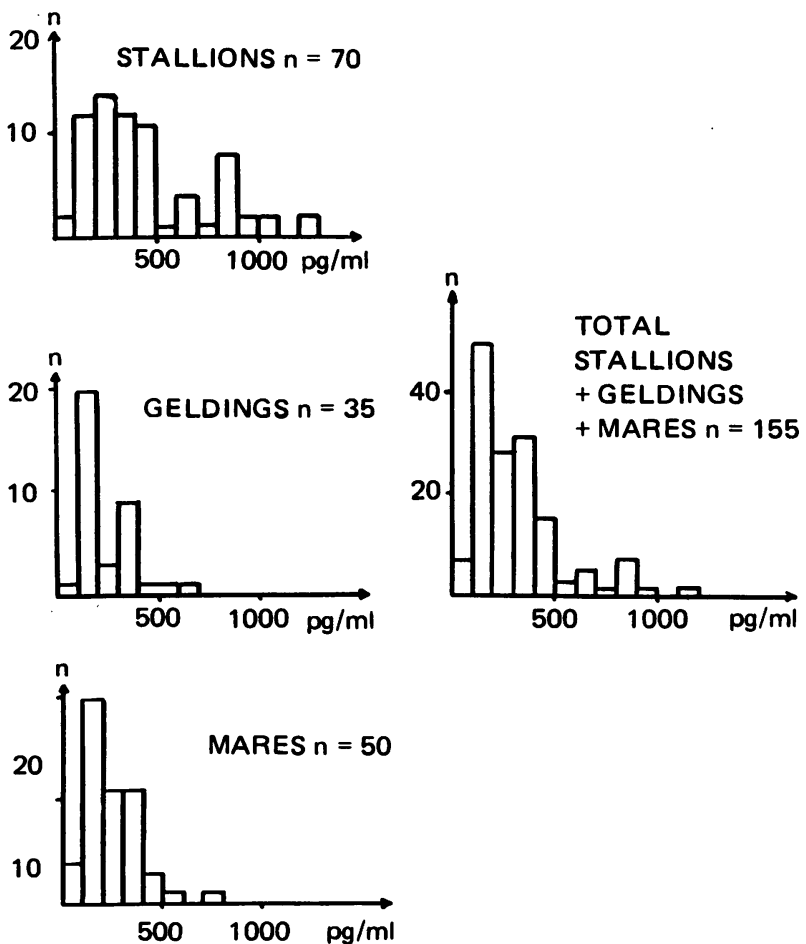

Fig. 2. Histograms of amounts of free testosterone in horses' urine according to sex.
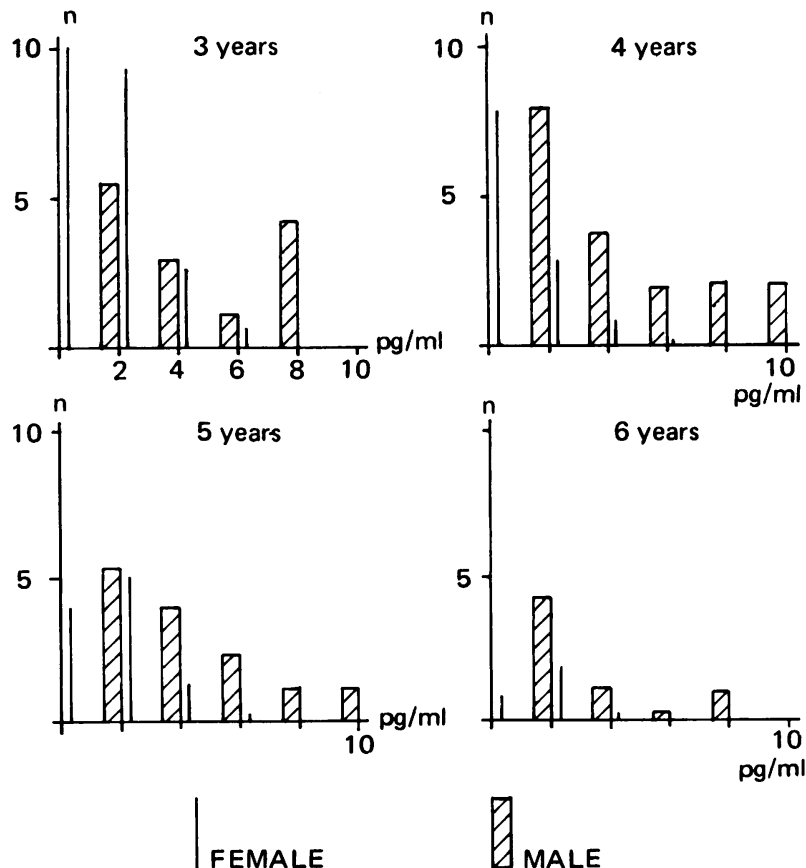

Fig. 3 Concentrations of testosterone in urine of stallions and females according to age. 
saliva even when the mucopolysaccharides it contains are removed.

Reasonable amounts of free hormone can be determined quite quickly in urine by this technique. The concentrations may vary greatly from one horse to the other and probably in the same horse according to time. However the concentration in stallion urine is greater than in urine from mares or geldings and the amount of hormone seems to decrease with age.
Occasionally, high concentrations were found, above $1000 \mathrm{pg} / \mathrm{ml}$, and only in stallion urine.

Storage of urines with preservatives like merseptyl act well, but it is worth keeping the urines at $4^{\circ} \mathrm{C}$ when possible.

Routine testing can be done as large number of determinations can be performed in the same series (about 25).

\section{DISCUSSION}

JONDORF: We have started testing some routine samples, not all from winners just a population of post-race samples. I find using the nortestosterone antibody that there are consistencies on the base lines for the geldings and mares but the stallion population of urines is identical with what you have. There appears to be two types of urine, as you have found using the testosterone antibodies and we find likewise using the nortestosterone antibodies. We do not know the explanation and do not find it related to age.

JOUANY: Among these 155 samples just one was about 1,200 so was suspected to be the consequence of a dope, but perhaps it is a special horse with 1,200 picograms of testosterone - an exception.

JONDORF: Because we found this great variation in stallion urine, we collected a series of samples from a normal stallion at the Equine Research Station, to see if there was some internal consistency from the same horse, and we found that there was. There did not appear to be any great diurnal variation in the materials reacting with nortestosterone antibodies in the horse.

HOUGHTON: Is your antibody specific for testosterone?

JOUANY: I am not sure. I forgot to say that we tried the method with blood and it works well, but it is impossible with saliva. We found 3,000 picograms per millilitre of saliva of the mares but that is probably not normal and was because of the mucopolysaccharides of the saliva which interferred very powerfully, so for radioimmunoassay of saliva you have to get rid of these mucopolysaccharides. 